Subscriber access provided by Caltech Library

\title{
Letter
}

\section{Si Microwire-Array Photocathodes Decorated with Cu Allow CO Reduction with Minimal Parasitic Absorption of Sunlight}

Paul Andrew Kempler, Matthias H. Richter, Wen-Hui Cheng, Bruce S. Brunschwig, and Nathan S. Lewis ACS Energy Lett., Just Accepted Manuscript • DOI: 10.1021/acsenergylett.0c01334 • Publication Date (Web): 07 Jul 2020

Downloaded from pubs.acs.org on July 7, 2020

\section{Just Accepted}

"Just Accepted" manuscripts have been peer-reviewed and accepted for publication. They are posted online prior to technical editing, formatting for publication and author proofing. The American Chemical Society provides "Just Accepted" as a service to the research community to expedite the dissemination of scientific material as soon as possible after acceptance. "Just Accepted" manuscripts appear in full in PDF format accompanied by an HTML abstract. "Just Accepted" manuscripts have been fully peer reviewed, but should not be considered the official version of record. They are citable by the Digital Object Identifier (DOI®). "Just Accepted" is an optional service offered to authors. Therefore, the "Just Accepted" Web site may not include all articles that will be published in the journal. After a manuscript is technically edited and formatted, it will be removed from the "Just Accepted" Web site and published as an ASAP article. Note that technical editing may introduce minor changes to the manuscript text and/or graphics which could affect content, and all legal disclaimers and ethical guidelines that apply to the journal pertain. ACS cannot be held responsible for errors or consequences arising from the use of information contained in these "Just Accepted" manuscripts. 


\title{
Si Microwire-Array Photocathodes Decorated with $\mathrm{Cu}$ Allow $\mathrm{CO}_{2}$ Reduction with Minimal Parasitic Absorption of Sunlight
}

\author{
Paul A. Kempler ${ }^{1}$, Matthias H. Richter ${ }^{1}$, Wen-Hui Cheng ${ }^{2}$, \\ Bruce S. Brunschwig ${ }^{3}$, Nathan S. Lewis ${ }^{1,3^{*}}$ \\ ${ }^{1}$ Division of Chemistry and Chemical Engineering, California Institute of Technology, Pasadena, \\ CA 91125 \\ ${ }^{2}$ Division of Engineering and Applied Science, California Institute of Technology, Pasadena, \\ CA 91125 \\ ${ }^{3}$ Beckman Institute, California Institute of Technology, Pasadena, CA 91125 \\ *Corresponding Author: nslewis@caltech.edu
}




\title{
TOC
}

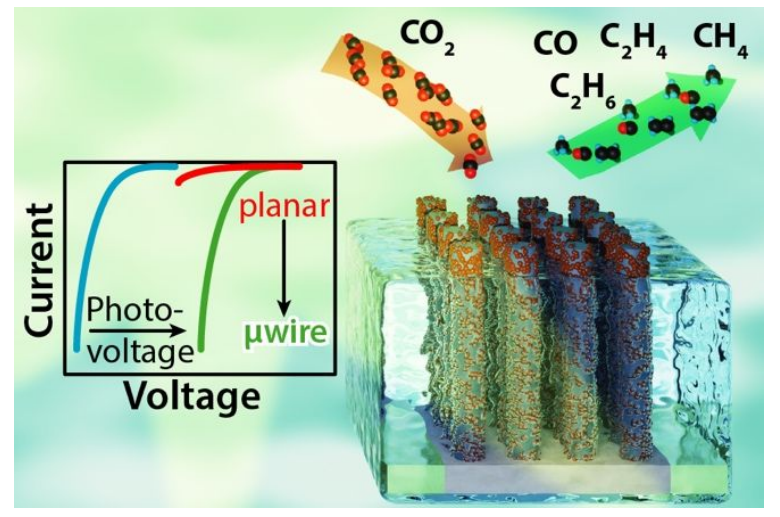

\begin{abstract}
:
High loadings of $\mathrm{Cu}$ were integrated on the light-facing side of Si microwire arrays used under simulated sunlight for the photoelectrochemical reduction of $\mathrm{CO}_{2}(\mathrm{aq})$ to hydrocarbons in 0.10 $\mathrm{M} \mathrm{KHCO}_{3}(\mathrm{aq})$. Radial-junction $\mathrm{n}^{+} \mathrm{p}-\mathrm{Si}$ microwire arrays decorated with $\mathrm{Cu}$ exhibited absolute photocurrent densities comparable to an uncovered Si surface. Moreover, with respect to a $\mathrm{Cu}$ foil electrode, the positive shift in the onset potential for hydrocarbon formation at $\mathrm{n}^{+} \mathrm{p}-\mathrm{Si} / \mathrm{Cu}$ microwire arrays was equal to or greater than the photovoltage of the semiconductor alone. Selective electrodeposition of $\mathrm{Cu}$ on the tips and sidewalls of Si microwires was responsible for the minimal parasitic reflection and absorption exhibited by the catalyst, such that light-limited, absolute current densities $>25 \mathrm{~mA} \cdot \mathrm{cm}^{-2}$ were sustained for $48 \mathrm{~h}$ under simulated sunlight. Photoelectrodes prepared from semiconductors with low diode quality factors and electrocatalysts with large Tafel slopes are shown to benefit from increased microstructured surface area. Si microwire arrays are thus suitable for photoelectrochemical reactions requiring high loadings of metallic and reflective electrocatalysts.
\end{abstract}


Electrochemical reduction of carbon dioxide, $\mathrm{CO}_{2} \mathrm{R}$, to carbon monoxide, ${ }^{1-2}$ methane, ethylene,,$^{3-4}$ and other reduced hydrocarbons and oxygenates provides a method of converting an industrial waste product into a feedstock for commodity chemicals and fuels. ${ }^{5}$ Both the activity and selectivity towards the generation of hydrocarbons can be controlled via the preparation of new intermetallic and alloy materials, ${ }^{6}$ but the sum of the absolute partial current densities towards hydrocarbons, $\left|j_{\mathrm{HC}}\right|$, at such catalysts is typically $<1 \mathrm{~mA} \cdot \mathrm{cm}^{-2}$ at overpotentials $<0.5 \mathrm{~V} \cdot{ }^{7-8}$ Under $1 \mathrm{~atm}$ of $\mathrm{CO}_{2}(\mathrm{~g})$ and modest overpotentials, $<0.5 \mathrm{~V}$, the reduction of $\mathrm{CO}_{2}$ is kinetically limited as opposed to mass-transport limited. Therefore, at a given potential, use of nanostructured, high surface area catalysts will yield an increased $\left|j_{\mathrm{HC}}\right| \cdot{ }^{9-10}$

Photoelectrochemical $\mathrm{CO}_{2} \mathrm{R}$, wherein accumulated photogenerated charge carriers lead to a positive shift in the potential required to effect the electrochemical reduction, requires appropriate integration of semiconductors and catalysts. ${ }^{11}$ Catalysts must be placed on a semiconductor in a fashion that allows collection of photogenerated charge carriers without blocking light from reaching the semiconductor. ${ }^{12}$ Increasing the loading of micron-scale catalyst particles at a planar surface typically leads to a linear trade-off in the amount of light which is collected by the semiconductor. ${ }^{13}$ Microstructured semiconductors can decouple the relationship between catalyst loading and the light-limited photocurrent density if additional catalyst particles do not add light-obscuring projected area (Scheme 1). ${ }^{14}$ Vertically oriented Si microwire, $\mu \mathrm{W}$, arrays infilled with nanoparticulate CoP catalysts on the substrate exhibited a photocurrent that was sensitive to the catalyst loading. ${ }^{15}$ In contrast, $\mu \mathrm{W}$ arrays with catalysts placed selectively on sidewalls of the microwires exhibited stable, high photocurrents densities, $J_{\mathrm{ph}}$, towards the hydrogen-evolution reaction (HER). ${ }^{16-17}$ 


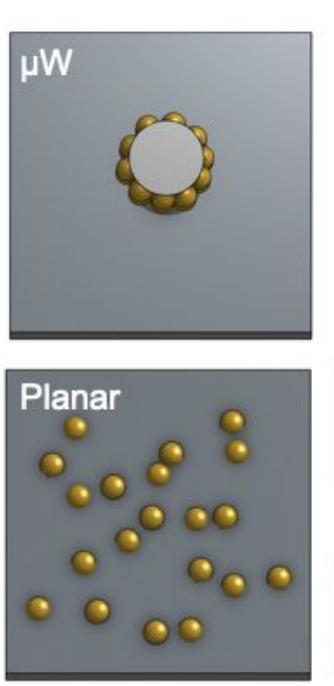

Normal incidence

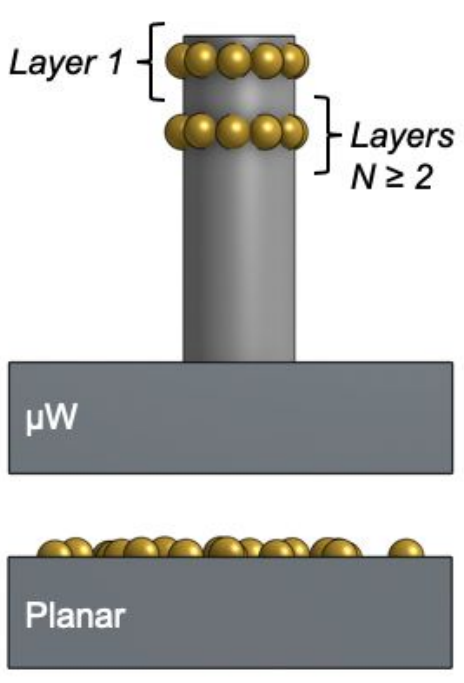

Cross section

Scheme 1: Identical catalyst loadings on microstructured and planar semiconductors showing the different effects of light blocking at normal incidence. Relative to a planar surface, the shaded area produced by a single hemisphere located on a vertical $\mu \mathrm{W}$ sidewall is reduced by approximately a factor of two (Layer 1) and additional layers of catalyst particles (Layers $N \geq 2$ ) do not contribute significantly to shaded areas on the semiconductor.

Nanostructured semiconductors have previously been used as photocathodes for $\mathrm{CO}_{2} \mathrm{R}$ that produce $\mathrm{CO}$, but not hydrocarbons. Silicon decorated with Ag nanoparticles during metal-assisted chemical etching was illuminated with $50 \mathrm{~mW} \cdot \mathrm{cm}^{-2}$ of simulated sunlight and exhibited absolute photocurrent densities of $8 \mathrm{~mA} \cdot \mathrm{cm}^{-2}$ at $-0.5 \mathrm{~V}$ vs. the reversible hydrogen electrode (RHE), with > 80\% Faradaic efficiency towards $\mathrm{CO} .{ }^{18}$ Silicon nanowires decorated with $\mathrm{Au}_{3} \mathrm{Cu}$ nanoparticles and under $20 \mathrm{~mW} \cdot \mathrm{cm}^{-2}$ of $740 \mathrm{~nm}$ illumination exhibited an absolute photocurrent density $>5.5$ $\mathrm{mA} \cdot \mathrm{cm}^{-2}$ at $-0.4 \mathrm{~V}$ vs. RHE with $67 \%$ Faradaic efficiency towards CO. ${ }^{19}$ The generation of hydrocarbons has been reported at Si-based photocathodes, but when the catalyst is loaded on the light-facing side of the photoelectrode absolute photocurrent densities, $\left|J_{\mathrm{ph}}\right|$, have been limited to $<2 \mathrm{~mA} \cdot \mathrm{cm}^{-2}$ at potentials less negative than $-1.0 \mathrm{~V}$ vs. RHE. ${ }^{20-21}$ Larger absolute photocurrent 
densities can be obtained when the catalyst is not in the path of incident illumination. For example, a $\mathrm{Cu}-\mathrm{Ag}$ alloy has been integrated onto the dark-facing side of a $\mathrm{p}^{+} \mathrm{nn}^{+}-\mathrm{Si}$ light absorber and produced $\left|J_{\mathrm{ph}}\right|>30 \mathrm{~mA} \cdot \mathrm{cm}^{-2}$ at $-1.1 \mathrm{~V}$ vs. RHE under $100 \mathrm{~mW} \cdot \mathrm{cm}^{-2}$ of Air Mass (AM) 1.5 simulated sunlight. ${ }^{22}$

Herein, we investigate whether Si $\mu \mathrm{W}$-arrays can minimize trade-offs between catalyst loading and light collection for light-facing photocathodes effecting $\mathrm{CO}_{2} \mathrm{R}$ to hydrocarbons. We demonstrate a Si photocathode with $\mathrm{Cu}$ electrodeposited onto the vertical sidewalls of high aspectratio microwires that exhibits minimal parasitic absorption by the catalyst with a maximum $\left|J_{\mathrm{ph}}\right|>$ $25 \mathrm{~mA} \cdot \mathrm{cm}^{-2}$ before and after $48 \mathrm{~h}$ of photoelectrochemical $\mathrm{CO}_{2} \mathrm{R}$ conditions, leading to the generation of $\mathrm{C}_{2} \mathrm{H}_{4}$ at more positive potentials than previously reported for photocathodes under 1-Sun illumination. The positive shift in the onset potential for $\mathrm{C}_{2} \mathrm{H}_{4}$ production, relative to that of a polished $\mathrm{Cu}$ foil electrode, exceeded the photovoltage of the $\mathrm{n}^{+} \mathrm{p}-\mathrm{Si} \mu \mathrm{W}$ array electrode due to the increased surface area within the internal volume of the $\mu \mathrm{W}$ array. An analytical expression is presented to express the effect of microstructure on the current density vs. potential $(J-E)$ behavior of a photoelectrode, as a function of the diode quality factor of the semiconductor and the Tafel slope of the electrocatalyst.

Figure 1 compares the photoelectrochemical behavior of planar $n^{+} p-S i$ to the behavior of a radially doped $\mathrm{n}^{+} \mathrm{p}$-Si $\mu \mathrm{W}$-array electrode. A schematic of the photoelectrochemical cell is presented in Figure 1a. A comparison of the $J-E$ behavior of illuminated planar $\mathrm{n}^{+} \mathrm{p}-\mathrm{Si} / \mathrm{Cu}$ and $\mathrm{n}^{+} \mathrm{p}$-Si $\mu \mathrm{W} / \mathrm{Cu}$ electrodes in the plating cell before and after, respectively, $-1.00 \mathrm{C} \cdot \mathrm{cm}^{-2}$ of charge passed towards $\mathrm{Cu}$ deposition is presented in Figure 1b. For the planar $\mathrm{n}^{+} \mathrm{p}$-Si electrode, $\left|J_{\mathrm{ph}}\right|$ at 0.2 V vs. the saturated calomel electrode (SCE) decreased by $29 \%$ of its initial value, whereas $\left|J_{\text {ph }}\right|$ for the $\mu \mathrm{W}$-array electrode remained unchanged from its initial value. The photocurrent at $0.0 \mathrm{~V}$ 
vs. SCE versus $\mathrm{Cu}$ loading, as measured by the cathodic charge density passed, is presented in Figure 1c. Initially, both the planar and $\mu \mathrm{W}$ electrode had similar photocurrent densities. However, for the planar, $\mathrm{n}^{+} \mathrm{p}-\mathrm{Si},\left|J_{\mathrm{ph}}\right|$ continuously decreased with increased loadings of $\mathrm{Cu}$, whereas at the $\mathrm{n}^{+} \mathrm{p}-\mathrm{Si} \mu \mathrm{W}$ electrode, $\left|J_{\mathrm{ph}}\right|$ increased and then remained nearly constant. The $J-E$ behavior at a graphite electrode was unchanged after the electrodeposition of $\mathrm{Cu}$ (Figure S2). Planar and $\mu \mathrm{W}$ electrodes exhibited $\left|J_{\mathrm{ph}}\right|=17.9$ and $26.0 \mathrm{~mA} \cdot \mathrm{cm}^{-2}$ after -148 and $-1000 \mathrm{C} \cdot \mathrm{cm}^{-2}$, respectively, had been passed towards $\mathrm{Cu}$ deposition. These geometric charge densities were equivalent after renormalization to the greater microstructured area of the $\mu \mathrm{W}$ array and thus the photoelectrochemical behavior was not solely a function of microstructured area.
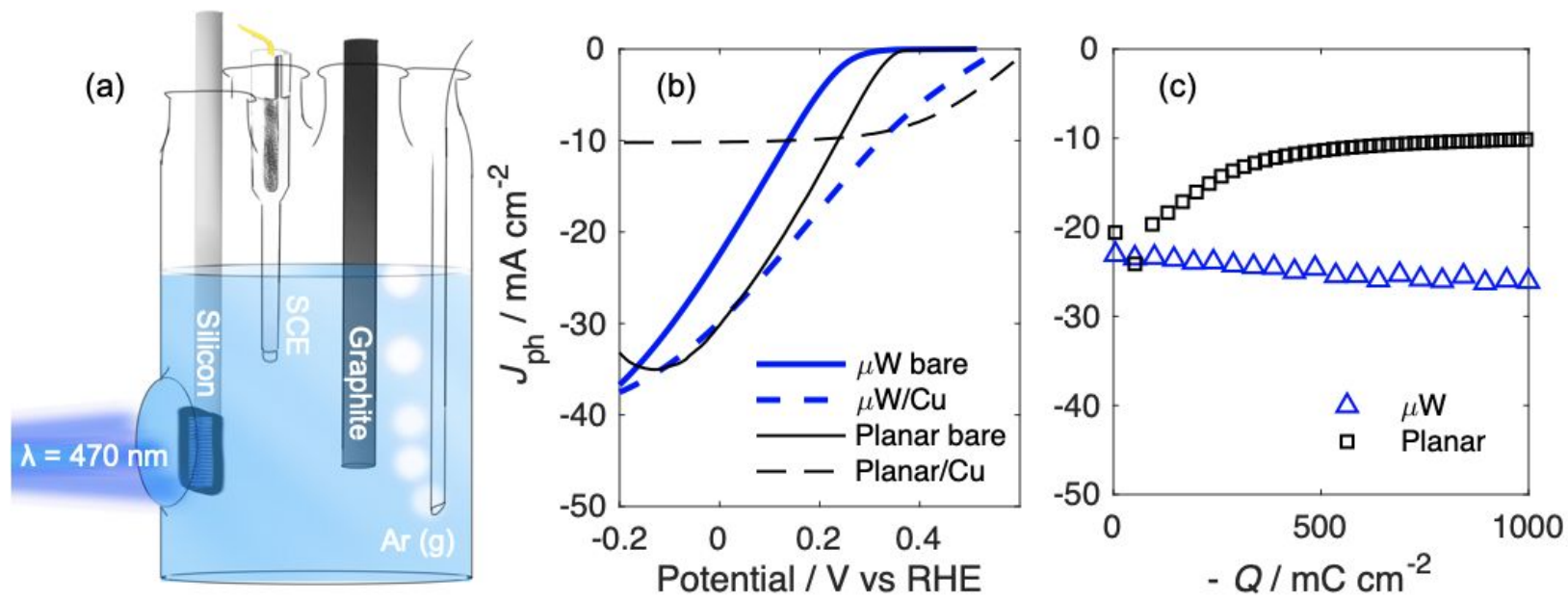

Figure 1: (a) Cell schematic for the photoelectrochemical deposition of $\mathrm{Cu}$ onto $\mathrm{n}^{+} \mathrm{p}$-Si. (b) Photoelectrochemical $J_{\mathrm{ph}}-E$ behavior of $\mathrm{n}^{+} \mathrm{p}-\mathrm{Si} \mu \mathrm{W}$ (blue lines) and planar $\mathrm{n}^{+} \mathrm{p}$-Si (black lines) in an Ar purged $\mathrm{Cu}$ deposition bath, before (solid) and after (dashed) passage of $-1.00 \mathrm{C} \cdot \mathrm{cm}^{-2}$. Linear sweep voltammograms were recorded at $-200 \mathrm{mV} \cdot \mathrm{s}^{-1}$. (c) $J_{\mathrm{ph}}-Q$ behavior for $\mathrm{n}^{+} \mathrm{p}-\mathrm{Si} \mu \mathrm{W}$ and planar $\mathrm{n}^{+} \mathrm{p}$-Si during photoelectrochemical deposition of $\mathrm{Cu}$ at $0.0 \mathrm{~V}$ vs. SCE.

Scanning-electron micrograph, SEM, images of electrodeposited $\mathrm{Cu}$ on planar $\mathrm{n}^{+} \mathrm{p}-\mathrm{Si}$ and $\mathrm{n}^{+} \mathrm{p}$-Si $\mu \mathrm{W}$ electrodes are presented as Figure 2. On the planar electrode, $\mathrm{Cu}$ electrodeposited as discontinuous particles that began to merge at high loadings, leading to nearly continuous islands 


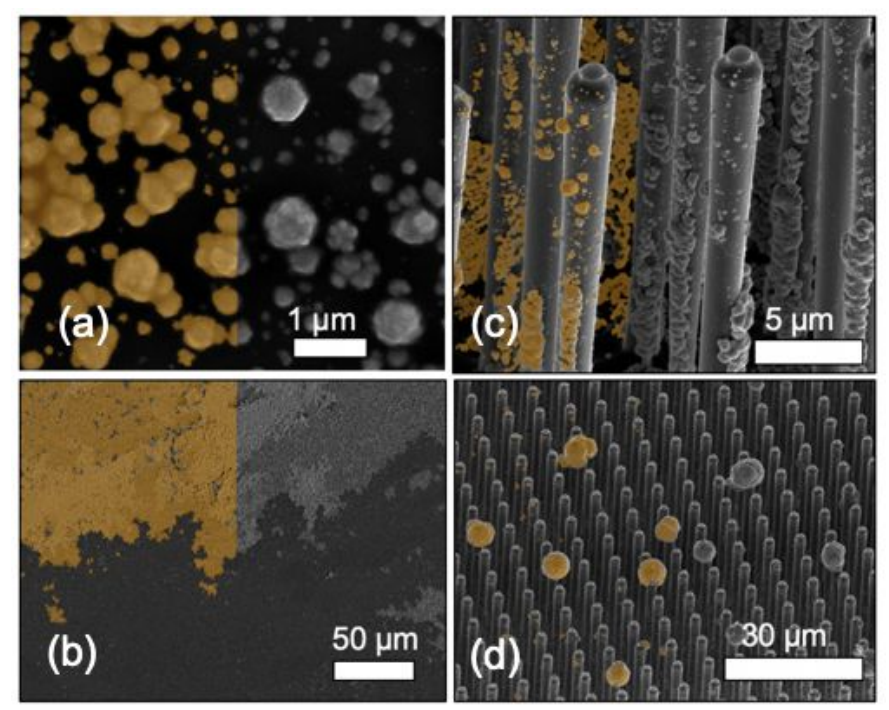

that were distributed unevenly and were prone to delamination (Figure 2a-b). In contrast, on $\mathrm{n}^{+} \mathrm{p}$ Si $\mu \mathrm{W}$ electrodes, nominally identical $\mathrm{Cu}$ loadings, as measured by the geometric charge density passed, led to discontinuous catalyst films that were distributed across the tips, sidewalls, and base of the $\mu \mathrm{W}$ array (Figure 2c). The Si $\mu \mathrm{W}$-array was composed of cylinders with a nominal diameter, pitch, and height of 3,7 , and $30 \mu \mathrm{m}$, respectively, leading to a microstructured area 6.8 times that of a planar surface. A few $\mathrm{Cu}$ particles $\sim 5 \mu \mathrm{m}$ in diameter were visible on the tips of individual wires (Figure 2d).

Figure 2: False-color SEM images of $\mathrm{Cu}$ (orange) photoelectrodeposited onto planar $\mathrm{n}^{+} \mathrm{p}$ Si after (a) $-148 \mathrm{mC} \cdot \mathrm{cm}^{-2}$ (b) and $-1.00 \mathrm{C} \cdot \mathrm{cm}^{-2}$ geometric charge density had been passed. (c-d) $\mathrm{n}^{+} \mathrm{p}-\mathrm{Si} \mu \mathrm{W}$ after a geometric charge density of $-1.00 \mathrm{C} \cdot \mathrm{cm}^{-2}$ had been passed.

The $\mathrm{n}^{+} \mathrm{p}$-Si $\mu \mathrm{W} / \mathrm{Cu}$ electrodes were evaluated as photocathodes for $\mathrm{CO}_{2} \mathrm{R}$, with online GCFID/TCD detection of gaseous products, to determine the activity of the microstructured catalyst film and the effects of the photovoltage on the product distribution. Figure 3a compares the $J-E$ behavior of an electropolished $\mathrm{Cu}$ foil in the dark to an illuminated $\mathrm{n}^{+} \mathrm{p}-\mathrm{Si} \mu \mathrm{W} / \mathrm{Cu}$ electrode in $0.10 \mathrm{M} \mathrm{KHCO}_{3}$ saturated with $\mathrm{CO}_{2}(\mathrm{~g})$ at $1 \mathrm{~atm}$. Illumination produced a substantial positive shift in the onset of cathodic current, with a saturated $\left|J_{\mathrm{ph}}\right|$ of $31 \pm 3 \mathrm{~mA} \cdot \mathrm{cm}^{-2}$ observed at $-0.62 \mathrm{~V}$ vs. 
RHE. The partial current density behaviors, $j_{\mathrm{x}}-E$, of $\mathrm{Cu}$ deposited on $\mathrm{n}^{+} \mathrm{p}-\mathrm{Si} \mu \mathrm{W}$ catalyzing the formation of $\mathrm{CO}, \mathrm{CH}_{4}$, and $\mathrm{C}_{2} \mathrm{H}_{4}$ consistently shifted towards more positive potentials, with the magnitude of the shift varying for different reduction products (Figures 3, S3). The activity of $\mathrm{n}^{+} \mathrm{p}$-Si $\mu \mathrm{W} / \mathrm{Cu}$ electrodes towards $\mathrm{H}_{2}$ was larger than that of a $\mathrm{Cu}$ foil (Figures S3, S4). The $\mathrm{n}^{+} \mathrm{p}-$ Si $\mu \mathrm{W} / \mathrm{Cu}$ electrode exhibited a peak $\left|j_{\mathrm{C} 2 \mathrm{H} 4}\right|$ of $2.1 \pm 0.2 \mathrm{~mA} \cdot \mathrm{cm}^{-2}$ at a potential of $-0.44 \mathrm{~V}$ vs. RHE, and the peak $\left|j_{\mathrm{CH} 4}\right|$ of $2.9 \pm 0.7 \mathrm{~mA} \cdot \mathrm{cm}^{-2}$ was observed at $-0.62 \mathrm{~V}$ vs. RHE. The total $\left|j_{\mathrm{HC}}\right|$ at $E=-$ $0.44 \mathrm{~V}$ vs. RHE was $4.1 \pm 0.2 \mathrm{~mA} \cdot \mathrm{cm}^{-2}$. Onset potentials for $\mathrm{H}_{2}$ and $\mathrm{CO}$ were positive of RHE, while those for of $\mathrm{C}_{2} \mathrm{H}_{4}$ and $\mathrm{CH}_{4}$ generation were observed at $-0.09 \mathrm{~V}$ vs. RHE.

Delamination of $\mathrm{Cu}$ films from planar $\mathrm{n}^{+} \mathrm{p}-\mathrm{Si} / \mathrm{Cu}$ electrodes during electrolysis led to increasing photocurrents and decreasing activity towards photoelectrochemical $\mathrm{CO}_{2} \mathrm{R}$. The average $j_{\mathrm{CH} 4}$ was $-0.9 \pm 0.3 \mathrm{~mA} \cdot \mathrm{cm}^{-2}$ and $-0.7 \pm 0.3 \mathrm{~mA} \cdot \mathrm{cm}^{-2}$, during the first $10 \mathrm{~min}$ of electrolysis, for $\mathrm{n}^{+} \mathrm{p}-\mathrm{Si} / \mathrm{Cu}$ photoelectrodes having a catalyst loading of $-148 \mathrm{mC} \cdot \mathrm{cm}^{-2}$ and $-1.00 \mathrm{C} \cdot \mathrm{cm}^{-2}$, respectively (Figure S5). The declined activity of planar $\mathrm{n}^{+} \mathrm{p}-\mathrm{Si} / \mathrm{Cu}$ electrodes within the first 20 min of controlled potential electrolysis prevented a quantitative assessment of the $J$ - $E$ behavior. The loss in activity was likely due to passivation of the $\mathrm{Si} / \mathrm{Cu}$ interface and/or more rapid poisoning of the reduced catalyst surface area relative to the behavior of $\mathrm{Cu}$ in $\mathrm{Si} \mu \mathrm{W}$-arrays.
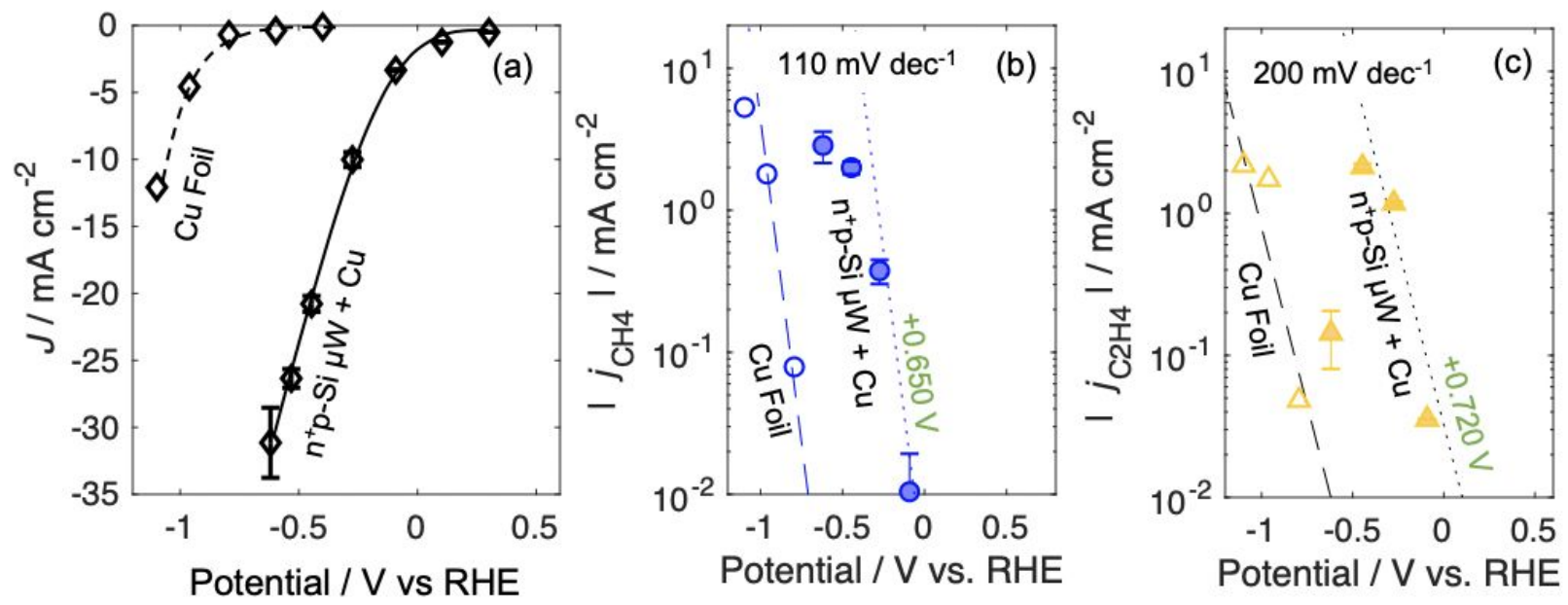
Figure 3: (a) Comparison of the electrochemical $J-E$ behavior of electropolished $\mathrm{Cu}$ in $0.10 \mathrm{M} \mathrm{KHCO}_{3}(\mathrm{aq})$ to the photoelectrochemical $J_{\mathrm{ph}^{-}} E$ behavior of $\mathrm{n}^{+} \mathrm{p}-\mathrm{Si} \mu \mathrm{W}$ under $100 \mathrm{~mW} \cdot \mathrm{cm}^{-}$ 2 simulated sunlight in a nominally identical electrochemical cell. (b) Absolute partial current density towards $\mathrm{CH}_{4}$ vs. potential, $j_{\mathrm{CH} 4}-E$, behavior measured via online GC-FID/TCD, for electropolished $\mathrm{Cu}$ (open markers) and $\mathrm{n}^{+} \mathrm{p}-\mathrm{Si} \mu \mathrm{W}$ (filled markers). (c) Absolute partial current density towards $\mathrm{C}_{2} \mathrm{H}_{4}$ vs. potential, $j_{\mathrm{C} 2 \mathrm{H} 4}-E$, behavior measured via online GC-FID/TCD, for electropolished $\mathrm{Cu}$ (open markers) and $\mathrm{n}^{+} \mathrm{p}-\mathrm{Si} \mu \mathrm{W}$ (filled markers). Measured partial current densities below $10 \mu \mathrm{A} \cdot \mathrm{cm}^{-2}$ were assumed to be lower than the limit of quantification of the technique and have been omitted from semi-log plots. Guidelines in (b,c) represent predicted behavior from measured Tafel slopes and photovoltages (vide infra).

The stability of $\mathrm{n}^{+} \mathrm{p}-\mathrm{Si} \mu \mathrm{W} / \mathrm{Cu}$ electrodes was investigated via extended chronoamperometry at $-0.58 \mathrm{~V}$ vs. RHE under $100 \mathrm{~mW} \cdot \mathrm{cm}^{-2}$ of Air Mass (AM) 1.5 simulated sunlight (details on intensity calibrations are provided in the Supporting Information). After an initial increase in $\left|J_{\mathrm{ph}}\right|$ upon reduction of $\mathrm{Cu}$ to its metallic state, the maximum photocurrent density remained stable for $48 \mathrm{~h}$ under constant potential (Figure S6a). The $J-E$ behavior of the $\mathrm{n}^{+} \mathrm{p}-\mathrm{Si}$ $\mu \mathrm{W} / \mathrm{Cu}$ electrode, as measured via linear sweep voltammetry at a scan rate of $-50 \mathrm{mV} \cdot \mathrm{s}^{-1}$ at $4 \mathrm{~h}$ intervals during the chronoamperometry, indicated that the optical properties of the integrated $\mathrm{Si} / \mathrm{Cu}$ microstructure, the photovoltage of the $\mathrm{n}^{+} \mathrm{p}$-Si junction, and the electrical resistance of the $\mathrm{Si} / \mathrm{Cu}$ interface remained stable after a brief initial period of activation (Figure S6a). Greater than $90 \%$ of the photocurrent density eventually resulted in the formation of $\mathrm{H}_{2}(\mathrm{~g})$ (Figure S6c). During continuous potential control of $\mathrm{n}^{+} \mathrm{p}-\mathrm{Si} \mu \mathrm{W} / \mathrm{Cu}$ electrodes at $-0.58 \mathrm{~V}$ vs. RHE, $\left|j_{\mathrm{C} 2 \mathrm{H} 4}\right|$ and $\left|j_{\mathrm{CH} 4}\right|$ decreased after 4 and 8 h, respectively, whereas $\left|j_{\mathrm{CO}}\right|$ increased with time (Figure S6d). Aqueous products were collected from the electrolyte in the cathode and anode compartments at the conclusion of the $48 \mathrm{~h}$ chronoamperometry stability experiment and were analyzed via HPLC. Formate, acetate, ethanol, and propanol were detected in both the anode and cathode 
compartments, but Faradaic efficiencies were not quantified (Table S1). SEM images of the $\mathrm{n}^{+} \mathrm{p}$ Si $\mu \mathrm{W}$ electrode (Figure S7) showed that the morphology of the deposited $\mathrm{Cu}$ catalyst particles changed during extended chronoamperometry, whereas the morphology of the Si $\mu \mathrm{W}$-array electrode remained unchanged.

Arrays of vertically-oriented Si $\mu$ Ws allow for high mass loadings of electrodeposited $\mathrm{Cu}$ on the light-facing side of photoelectrodes without substantial reductions in $\left|J_{\mathrm{ph}}\right|$ (Figure 1c). Despite the high $\left(0.33 \mathrm{mg} \cdot \mathrm{cm}^{-2}\right)$ mass loading of electrocatalyst on the light-facing side of the electrode (Equation $\mathrm{S} 1$ ), $\mathrm{n}^{+} \mathrm{p}-\mathrm{Si} \mu \mathrm{W} / \mathrm{Cu}$ electrodes exhibited absolute photocurrent densities $>30 \mathrm{~mA} \cdot \mathrm{cm}^{-2}$ under AM 1.5 simulated solar illumination. The predicted $\left|J_{\mathrm{ph}}\right|$ at a $500 \mu \mathrm{m}$ thick Si slab in air, under AM 1.5 simulated solar illumination is $29 \mathrm{~mA} \cdot \mathrm{cm}^{-2}$ and uncovered, planar $\mathrm{n}^{+} \mathrm{p}-$ Si in $0.50 \mathrm{M} \mathrm{H}_{2} \mathrm{SO}_{4}(\mathrm{aq})$ under $\mathrm{AM} 1.5$ simulated solar illumination exhibited a limiting $\left|J_{\text {ph }}\right|$ of $27.5 \mathrm{~mA} \mathrm{~cm}{ }^{-2} \cdot{ }^{23-24}$ The generation rate of hydrocarbons at $\mathrm{n}^{+} \mathrm{p}-\mathrm{Si} \mu \mathrm{W} / \mathrm{Cu}$ electrodes in $0.10 \mathrm{M} \mathrm{KHCO}_{3}(\mathrm{aq})$ saturated with $\mathrm{CO}_{2}(\mathrm{~g})$ matched or exceeded the performance of an electrode possessing the electrocatalytic activity of an electropolished $\mathrm{Cu}$ film in series with the photovoltage of a microstructured Si photovoltaic (Figure 3).

The yield of hydrocarbon and oxygenate products in the (photo)electrochemical $\mathrm{CO}_{2} \mathrm{R}$ is a function of both the catalyst used and the overpotential. Decreasing the coverage of catalysts on a photoelectrode can lead to increased light transmission, photocurrent, and photovoltage but will adversely affect the total rate of reaction if kinetic losses at the catalysts are not overcome by the increased photovoltage. Furthermore, the regions responsible for catalysis and light absorption must be within the diffusion length of the excited charge carriers to prevent losses due to carrier recombination. Microstructured semiconductors provide additional surface area for light collection and electrocatalysis, but must overcome a reduction in photovoltage due to the increased surface 
area available for recombination. The photovoltage, $V_{\mathrm{ph}}$, provided by a microstructured semiconductor with a junction uniformly distributed across the surface is described by Equation 1:

$$
V_{\mathrm{ph}}(J)=-\frac{2.3 n k_{b} T}{q} \log _{10}\left(\frac{\left|J_{\mathrm{ph}}\right|-|J|}{\left(R_{\mu}\right)\left|J_{o}\right|}+1\right)
$$

where $n$ is the diode quality factor, $k_{b}$ is Boltzmann's constant, $T$ is the operating temperature, $q$ is the unsigned elementary charge, $J_{\mathrm{o}}$ is the dark current density across the charge-separating junction, and $R_{\mu}$ is the ratio of the microstructured area to the geometric area. Current densities are normalized to the geometric area of the device. Equation 2 represents the $\eta$ - $J$ relationship at electrocatalysts on a microstructured electrode as described by the Tafel equation:

$$
\eta(J)=b \log _{10}\left(J / R_{\mu}\right)-a
$$

where $b$ is the measured Tafel slope and $a$ can be calculated from the measured exchange current density. ${ }^{25}$

The effect of increasing the microstructured area of a photoelectrode on the illuminated $j$ $E$ behavior can be described by the sum of Equations 1 and 2. Increasing the microstructured area at an ideal diode $(n=1)$ leads to a $60 \mathrm{mV} \cdot \mathrm{dec}^{-1}$ reduction in $\left|V_{\mathrm{ph}}\right|$, whereas the reduction in $|\eta|$ depends on the Tafel slope of the catalyst (Figure 4a). The Tafel slopes for $\mathrm{Cu}$ catalyzing $\mathrm{CO}_{2} \mathrm{R}$ to $\mathrm{CH}_{4}$ and $\mathrm{C}_{2} \mathrm{H}_{4}$ in $0.50 \mathrm{M} \mathrm{KHCO}_{3}(\mathrm{aq})$ have been reported as $110 \mathrm{mV} \cdot \mathrm{dec}^{-1}$ and $200 \mathrm{mV} \cdot \mathrm{dec}^{-1}$, respectively. ${ }^{26}$ Hence microstructured photocathodes prepared from ideal diodes decorated with $\mathrm{Cu}$ will produce $\mathrm{C}_{2} \mathrm{H}_{4}$ at more positive potentials than an equivalent planar photocathode (Figure 4b). For catalysts that exhibit small Tafel slopes $<60 \mathrm{mV} \cdot \mathrm{dec}^{-1}$, e.g. Pt effecting the HER at $\mathrm{pH} 0$ $\left(b=28 \mathrm{mV} \cdot \mathrm{dec}^{-1}\right)$, reductions in photovoltage will match or exceed reductions in the overpotential that result from microstructuring, leading to a negative potential shift in the $j-E$ behavior (Figure 4b). For $b=60-120 \mathrm{mV} \cdot \mathrm{dec}^{-1}$ the net effect of microstructuring depends on $n$, while for $b>120$ 
$\mathrm{mV} \cdot \mathrm{dec}^{-1}$, in the absence of mass transport limitations, reductions in $V_{\mathrm{ph}}$ will typically be fully offset by reductions in $\eta$ (Figure 4c).
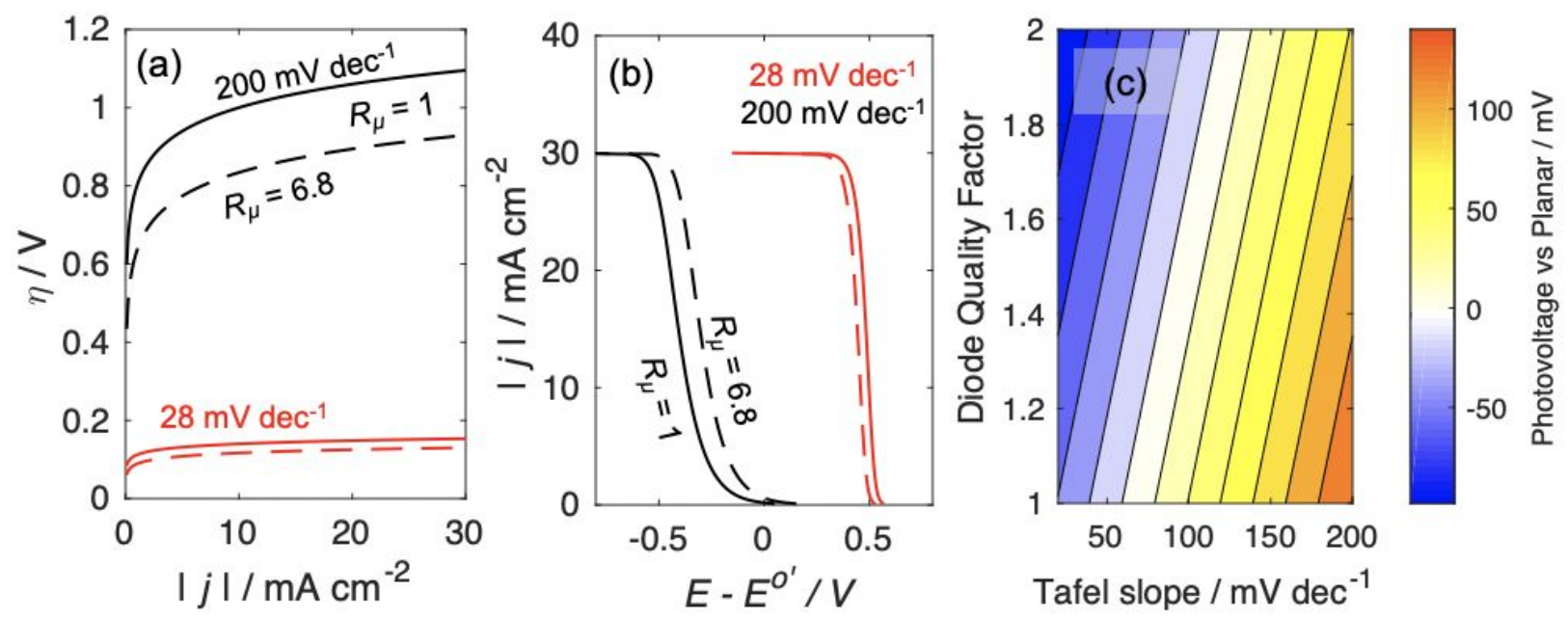

Figure 4: (a) $\eta$ - $J$ behavior for planar $\left(R_{\mu}=1\right)$, continuous lines, and $\mu \mathrm{W}\left(R_{\mu}=6.8\right)$, dashed lines, for electrocatalysts exhibiting $b=0.028$ and $0.200 \mathrm{~V} \cdot \mathrm{dec}^{-1}$, shown in red and black, respectively. (b) $j-E$ behavior calculated from the sum of Equations 1 and 2 for planar, continuous lines, and $\mu \mathrm{W}$, dashed lines, photocathodes as a function of $b$, for $J_{\mathrm{ph}}=30 \mathrm{~mA} \cdot \mathrm{cm}^{-2}$ and $n=1.3$. (c) Contour lines comparing the shift in photovoltage at $\left|J_{\mathrm{ph}}\right|=10 \mathrm{~mA} \cdot \mathrm{cm}^{-2}$, due to increasing $R_{\mu}$ by a factor of 10 , as a function of $n$ and $b$. Details on the calculations are provided in the Supporting Information.

The observations herein demonstrate that microstructured photoelectrodes can yield a positive shift in the $j-E$ behavior in excess of the photovoltage of a planar semiconductor, thereby increasing $j_{\mathrm{CO} 2 \mathrm{R}}$. Semi-log plots of $\left|j_{\mathrm{CH} 4}\right|$ and $\left|j_{\mathrm{C} 2 \mathrm{H} 4}\right|$ versus $E$ for planar and $\mu \mathrm{W} \mathrm{n}^{+} \mathrm{p}$-Si electrodes exhibited mutually similar Tafel slopes that were moreover in agreement with literature values (Figure 3b-c). ${ }^{26}$ Over a range of photocurrent densities relevant to solar-fuels device operation, planar $\mathrm{n}^{+} \mathrm{p}$-Si junctions $\left(R_{\mu}=1\right)$ exhibited $n=1.3$ and $J_{\mathrm{o}}=9 \times 10^{-10} \mathrm{~A} \cdot \mathrm{cm}^{-2}$, whereas $\mu \mathrm{W} \mathrm{n}^{+} \mathrm{p}-\mathrm{Si}$ junctions $\left(R_{\mu}=6.8\right)$ exhibited $n=2.5$ and $J_{\mathrm{o}}=7 \times 10^{-7} \mathrm{~A} \cdot \mathrm{cm}^{-2}$ (Figure S8). The value of $J_{\mathrm{o}}$ increased for the radial-junction relative to the planar junction, possibly as a consequence of the reactive-ion etching process. This explanation is consistent with the large value of $n$ observed at 
the $\mu \mathrm{W}$ junction. Relative to the planar $\mathrm{n}^{+} \mathrm{p}-\mathrm{Si}$ junction, the reduction in $\left|V_{\mathrm{ph}}\right|$ obtained at the $\mu \mathrm{W}$ $\mathrm{n}^{+} \mathrm{p}$-Si junction was less than the expected $V_{\text {ph }}$ based on changes to $J_{o}$, due to the simultaneous increase in $n$. At $\left|J_{\mathrm{ph}}\right|$ comparable to those observed under simulated sunlight $\left(30 \mathrm{~mA} \cdot \mathrm{cm}^{-2}\right)$, the $\mu \mathrm{W}$ junction yielded a $V_{\mathrm{ph}}$ that was $14 \mathrm{mV}$ less than the planar junction. Based on the increased catalyst area and the measured $V_{\mathrm{ph}}$, the predicted potential shifts in $j_{\mathrm{CH} 4}$ and $j_{\mathrm{C} 2 \mathrm{H} 4}$ at the $\mu \mathrm{W} \mathrm{n}^{+} \mathrm{p}$ $\mathrm{Si} / \mathrm{Cu}$ electrode are 0.650 and $0.720 \mathrm{~V}$, respectively. The $j_{\mathrm{C} 2 \mathrm{H} 4}-E$ data were in close agreement with the predicted values, while the $j_{\mathrm{CH} 4}-E$ data were shifted less positive, relative to polycrystalline $\mathrm{Cu}$, than the predicted shift (Figure 3b-c). Details on the calculations of the potential shift in $j_{\mathrm{x}}-E$ are provided in the Supporting Information.

The onset of photocurrent at front-side illuminated $\mathrm{n}^{+} \mathrm{p}-\mathrm{Si} \mu \mathrm{W} / \mathrm{Cu}$ electrodes was observed at potentials $>1 \mathrm{~V}$ more positive than those previously reported at $\mathrm{p}-\mathrm{Si} / \mathrm{Cu}$ electrodes. ${ }^{21}$ Planar $\mathrm{n}^{+} \mathrm{p}$-Si with $\mathrm{Cu}$ at low or high catalyst loadings did not produce $\mathrm{C}_{2} \mathrm{H}_{4}$ in quantities sufficient for quantification and exhibited $j_{\mathrm{CH} 4}<0.5 \mathrm{~mA} \cdot \mathrm{cm}^{-2}$ within 20 min of potential control at $-0.598 \mathrm{~V}$ vs. RHE. This behavior indicates that $\mathrm{Cu}$ loadings suitable for transmission of light on planar surfaces have low activity and/or electrochemical stability towards $\mathrm{CO}_{2} \mathrm{R}$. Glass with a $45 \mathrm{~nm} \mathrm{Cu}$ film reflects $>90 \%$ of photons at wavelengths $>600 \mathrm{~nm}$ and $>50 \%$ of photons at wavelengths between $400-600 \mathrm{~nm} .{ }^{27}\left|J_{\mathrm{ph}}\right|$ values obtained at planar and $\mu \mathrm{W} \mathrm{n}{ }^{+} \mathrm{p}-\mathrm{Si} / \mathrm{Cu}$ photocathodes were larger than what would be expected given coverage of the surface with a continuous film, consistent with the discontinuous coating of opaque metal islands observed via SEM (Figure 2b). Semiconductors that cannot be readily microstructured or which exhibit high diode quality factors could benefit from the use of transparent, high surface-area, conductive supports for metallic catalysts for $\mathrm{CO}_{2} \mathrm{R}^{28}$ 
High photocurrent densities were sustained at $n^{+} p-S i \mu W / C u$ photocathodes for $48 \mathrm{~h}$ of photoelectrochemical operation, demonstrating that the exposed $\mathrm{Si}$ surfaces were passivated towards dissolution and that the electrical contact between the light-absorber and catalyst islands was stable (Figures S6). Prior experimental results on the electrocatalytic activity of Cu towards $\mathrm{CH}_{4}$ and $\mathrm{C}_{2} \mathrm{H}_{4}$ in $0.1 \mathrm{M} \mathrm{KHCO}_{3}(\mathrm{aq})$ have been assessed on timescales $\leq 1 \mathrm{~h}$, commensurate with the stability of photoelectrodes in this work. ${ }^{4,} 29$ Experiments conducted in flowing electrolytes have yielded Faradaic efficiencies which are significantly more stable towards $\mathrm{CO}_{2} \mathrm{R} . \mathrm{A}\left|j_{\mathrm{CO}}\right|>$ $130 \mathrm{~mA} \mathrm{~cm}{ }^{-2}$ was demonstrated for $100 \mathrm{~h}$ at PTFE-supported $\mathrm{Ag}$ in flowing $1 \mathrm{M} \mathrm{KOH}(\mathrm{aq}) \cdot{ }^{30}$ Carbon-nanoparticle-supported $\mathrm{Cu}$ has yielded $\left|j_{\mathrm{C} 2 \mathrm{H} 4}\right| \geq 50 \mathrm{~mA} \mathrm{~cm}^{-2}$ for $150 \mathrm{~h}$ in flowing $7 \mathrm{M}$ $\mathrm{KOH}(\mathrm{aq}) .{ }^{31}$ Increases in $j_{\mathrm{H} 2}$ and $j_{\mathrm{CO}}$ with time at $\mathrm{n}^{+} \mathrm{p}-\mathrm{Si} \mu \mathrm{W} / \mathrm{Cu}$ photocathodes could be due to deposition of metal impurities from the solution either onto the $\mathrm{Cu}$ surface, reducing the catalytic efficiency of the $\mathrm{Cu}$ for $\mathrm{CO}_{2} \mathrm{R}$, or deposition unto the bare $\mathrm{Si}$ surface increasing its catalytic efficiency for $\mathrm{H}_{2}$ and $\mathrm{CO}$ (Figure S6). Crossover of dissolved $\mathrm{Pt}$ from the anode to the $\mathrm{Cu}$ or $\mathrm{Si}$ surface could play this role. X-ray photoelectron spectroscopy, XPS, and Auger spectroscopy measurements of a $\mathrm{Cu}$ film on Si before and after a series of $2 \mathrm{~h}$ experiments under potential control in $0.10 \mathrm{M} \mathrm{KHCO}_{3}(\mathrm{aq})$ did not reveal the presence of $\mathrm{Pt}$, but confirmed that $\mathrm{Cu}$ was reduced to a metallic state during electrochemical operation (Figure S9). Inductively-coupled plasma massspectrometry and XPS, following a 5 day galvanostatic experiment at $10 \mathrm{~mA}$ in $0.10 \mathrm{M}$ $\mathrm{KCHO}_{3}(\mathrm{aq})$ using a Pt foil anode and graphite cathode separated by a Selemion AMV membrane confirmed the presence of dissolved Pt in the anolyte and catholyte, and plating of metal onto the graphite surface (Table S2, Figure S10). The graphite cathode was chosen so that peaks in the Pt 4f region of the XPS data could be resolved without interference from the substantially more 
intense $\mathrm{Cu} 3$ p peak (Figure S9). Photoelectrochemical cells that use the same catalyst for both $\mathrm{CO}_{2} \mathrm{R}$ and water oxidation have been beneficially used to avoid such poisoning. ${ }^{32}$

Backside illuminated, textured Si photocathodes exhibit a $\left|j_{\mathrm{HC}}\right|$, of $<2 \mathrm{~mA} \cdot \mathrm{cm}^{-2}$ at $-0.4 \mathrm{~V}$ vs. RHE. ${ }^{25}$ Although the $\mathrm{n}^{+} \mathrm{p}-\mathrm{Si} \mu \mathrm{W} / \mathrm{Cu}$ photocathodes reported herein exhibited a larger total $\left|j_{\mathrm{HC}}\right|$ $>4 \mathrm{~mA} \cdot \mathrm{cm}^{-2}$ at $-0.44 \mathrm{~V}$ vs. RHE, substantially lower Faradaic efficiencies were observed towards $\mathrm{CO}_{2} \mathrm{R}$ relative to these previous reports. $\mathrm{Cu}$ supported on $\mathrm{Ag}$ has been shown to suppress the generation of $\mathrm{H}_{2}(\mathrm{~g})$ such that greater Faradaic efficiencies towards hydrocarbons can be obtained. ${ }^{33}$ $\mathrm{CuAg}$ alloys could be integrated onto $\mathrm{Si} \mu \mathrm{W}$-arrays to reduce the partial current density towards $\mathrm{H}_{2},{ }^{33}$ but at backside illuminated Si photocathodes the HER was not suppressed without complete coverage of the photocathode surface by catalyst, ${ }^{22}$ which is incompatible with the microstructuring strategy employed herein. Alternatively, suppression of the parasitic photocurrent density towards $\mathrm{H}_{2}$ by passivation of the exposed light absorbing regions with an insulating, chemically inert layer such as $\mathrm{SiN}_{\mathrm{x}}$ could lead to increased photovoltages and Faradaic efficiencies for $\mathrm{CO}_{2} \mathrm{R} .{ }^{16}$

The results from this work have important applications in designs for electrode systems that use $\mathrm{H}_{2} \mathrm{O}$ and $\mathrm{CO}_{2}$ to store sunlight as fuels. Mass loadings of $\mathrm{Cu}$, sufficient to meet the $j-E$ behavior of a $\mathrm{Cu}$ foil, can be deposited on the light-absorbing surface of a microstructured photocathode for which the reduction in overpotential due to the microstructured surface area can meet or exceed the reductions in photovoltage due to increased dark current. Microstructured semiconductors will be required to ensure efficient and stable solar-to-fuels generation so that membranes can be incorporated at length scales smaller than the minority-carrier diffusion length in the semiconductor. ${ }^{34}$ Although the $\mathrm{Si} \mu \mathrm{W}$ arrays in this work were formed via reactive-ion 
etching, similar structures can be grown from gas precursors such as $\mathrm{SiCl}_{4}$ and $\mathrm{SiH}_{4}$, over large areas, and have been used as efficient photocathodes. ${ }^{35}$

Electrochemical reactions that consume protons generate $\mathrm{pH}$ gradients that can lead to shifts in the product distribution. Previous studies on micro- and nanostructured cathodes have used proton-concentration gradients to suppress the hydrogen-evolution reaction and increase the Faradaic efficiency of Au towards $\mathrm{CO}$ production. ${ }^{36-37}$ The short, sparse microwire array used in this work exhibited a similar product distribution relative to the polished $\mathrm{Cu}$ foil. The Tafel slopes were also mutually similar for both types of electrodes. Future studies on densely packed microwire arrays with heights greater than the boundary layer thickness would enable the effects of concentration gradients of protons and $\mathrm{CO}_{2}(\mathrm{aq})$ within the electrode to be explored. In this work, photocathodes were operated under 1 atm of $\mathrm{CO}_{2}$ and at near-neutral $\mathrm{pH}$. In contrast, practical devices will require a concentrated source of $\mathrm{CO}_{2}$, higher $\mathrm{pH}$ values, forced convection of the electrolyte to minimize the thickness of the concentration boundary layer, and/or methods of interconverting $\mathrm{HCO}_{3}^{-}(\mathrm{aq})$ and $\mathrm{CO}_{2}$ (aq) to sustain $\left|J_{\mathrm{ph}}\right|$ equal or greater than the values reported herein for devices covering areas relevant to commercial, scalable fuel formation. ${ }^{38}$

Vertically oriented $\mathrm{Si} \mu \mathrm{W}$ arrays allowed for the integration of discontinuous, electrodeposited $\mathrm{Cu}$ films at mass-loadings sufficient to drive photoelectrochemical $\mathrm{CO}_{2} \mathrm{R}$ at overpotentials comparable to a continuous planar $\mathrm{Cu}$ film, while maintaining stable photocurrent densities comparable to those exhibited by a planar Si surface with no $\mathrm{Cu}$. Metallic catalysts that exhibit large Tafel slopes and primarily reflect, rather than absorb, light benefit from this method of semiconductor-catalyst integration. The $\left|J_{\mathrm{ph}}\right|$ obtained at the $\mathrm{n}^{+} \mathrm{p}-\mathrm{Si} \mu \mathrm{W} / \mathrm{Cu}$ electrodes under 1 Sun illumination in this work are among the highest reported values for photocathodes for $\mathrm{CO}_{2} \mathrm{R}$, independent of where the catalyst was located. Thus, semiconductors that can be structured into 
high-aspect-ratio features, larger than a wavelength of light, are suitable for integration with high loadings of metallic electrocatalysts for photoelectrochemical devices.

\section{ASSOCIATED CONTENT}

\section{Supporting Information}

The Supporting Information is available free of charge on the ACS Publications website. Additional methods, materials, calculation of mass loadings, explanation of $i R$ correction, explanation of simulated $j-E$ behaviors, a schematic of the testing cell, partial current densities and Faradaic efficiencies of $\mathrm{CO}_{2} \mathrm{R}$ products, measurements of the diode behaviors, stability measurements, XPS and Auger spectra, and Pt quantification are available.

\section{AUTHOR INFORMATION}

\section{Corresponding Author}

*E-mail: nslewis@caltech.edu

\section{ORCID}

Paul A. Kempler: 0000-0003-3909-1790

Matthias H. Richter: 0000-0003-0091-2045

Wen-Hui Cheng: 0000-0003-3233-4606

Bruce S. Brunschwig: 0000-0002-6135-6727

Nathan S. Lewis: 0000-0001-5245-0538

\section{Author Contributions}

Si- $\mu$ W Sample Fabrication, P.A.K., Cu foil preparation M.H.R.; Investigation, P.A.K. M.H.R. and W.H.C.; Writing, P.A.K., M.H.R., B.S.B. and N.S.L.; Funding Acquisition, N.S.L. and B.S.B.; Supervision, N.S.L. and B.S.B.

\section{Notes}

The authors declare no competing financial interest. 


\section{ACKNOWLEDGMENTS}

This work was supported through the Office of Science of the U.S. Department of Energy (DOE) under award no. DE SC0004993 to the Joint Center for Artificial Photosynthesis, a DOE Energy Innovation Hub. Fabrication of the Si microwire arrays was performed in the Kavli Nanoscience Institute (KNI) at Caltech, and we thank the KNI staff for their assistance during fabrication. XPS data were collected at the Molecular Materials Resource Center of the Beckman Institute.

\section{References}

1. Hori, Y.; Murata, A.; Kikuchi, K.; Suzuki, S., Electrochemical reduction of carbon dioxides to carbon monoxide at a gold electrode in aqueous potassium hydrogen carbonate. $J$. Chem. Soc., Chem. Commun. 1987, (10), 728-729.

2. Saberi Safaei, T.; Mepham, A.; Zheng, X.; Pang, Y.; Dinh, C.-T.; Liu, M.; Sinton, D.; Kelley, S. O.; Sargent, E. H., High-density nanosharp microstructures enable efficient $\mathrm{CO}_{2}$ electroreduction. Nano Lett. 2016, 16 (11), 7224-7228.

3. Hori, Y.; Murata, A.; Takahashi, R., Formation of hydrocarbons in the electrochemical reduction of carbon dioxide at a copper electrode in aqueous solution. J. Chem. Soc., Faraday Trans. 1 1989, 85 (8), 2309-2326.

4. Kuhl, K. P.; Cave, E. R.; Abram, D. N.; Jaramillo, T. F., New insights into the electrochemical reduction of carbon dioxide on metallic copper surfaces. Energy Environ. Sci. 2012, 5 (5), 7050-7059.

5. Kumaravel, V.; Bartlett, J.; Pillai, S. C., Photoelectrochemical conversion of carbon dioxide $\left(\mathrm{CO}_{2}\right)$ into fuels and value-added products. ACS Energy Lett. 2020.

6. Karamad, M.; Tripkovic, V.; Rossmeisl, J., Intermetallic alloys as CO electroreduction catalysts — role of isolated active sites. ACS Catal. 2014, 4 (7), 2268-2273. 
7. Kortlever, R.; Peters, I.; Balemans, C.; Kas, R.; Kwon, Y.; Mul, G.; Koper, M. T., Palladium-gold catalyst for the electrochemical reduction of $\mathrm{CO}_{2}$ to $\mathrm{C} 1-\mathrm{C} 5$ hydrocarbons. Chem. Commun. 2016, 52 (67), 10229-32.

8. Torelli, D. A.; Francis, S. A.; Crompton, J. C.; Javier, A.; Thompson, J. R.; Brunschwig, B. S.; Soriaga, M. P.; Lewis, N. S., Nickel-gallium-catalyzed electrochemical reduction of $\mathrm{CO}_{2}$ to highly reduced products at low overpotentials. ACS Catal. 2016, 6 (3), 2100-2104.

9. Wang, L.; Nitopi, S.; Wong, A. B.; Snider, J. L.; Nielander, A. C.; Morales-Guio, C. G.; Orazov, M.; Higgins, D. C.; Hahn, C.; Jaramillo, T. F., Electrochemically converting carbon monoxide to liquid fuels by directing selectivity with electrode surface area. Nat. Catal. 2019, 2 (8), 702-708.

10. Kumar, B.; Atla, V.; Brian, J. P.; Kumari, S.; Nguyen, T. Q.; Sunkara, M.; Spurgeon, J. M., Reduced $\mathrm{SnO}_{2}$ porous nanowires with a high density of grain boundaries as catalysts for efficient electrochemical $\mathrm{CO}_{2}$-into-HCOOH conversion. Angew. Chem. Int. Ed. Engl. 2017, 56 (13), 3645-3649.

11. Lewis, N. S., Developing a scalable artificial photosynthesis technology through nanomaterials by design. Nat. Nanotechnol. 2016, 11 (12), 1010-1019.

12. Trotochaud, L.; Mills, T. J.; Boettcher, S. W., An optocatalytic model for semiconductorcatalyst water-splitting photoelectrodes based on in situ optical measurements on operational catalysts. J. Phys. Chem. Lett. 2013, 4 (6), 931-935.

13. Chen, Y.; Sun, K.; Audesirk, H.; Xiang, C.; Lewis, N. S., A quantitative analysis of the efficiency of solar-driven water-splitting device designs based on tandem photoabsorbers patterned with islands of metallic electrocatalysts. Energy Environ. Sci. 2015, 8 (6), 1736-1747. 
14. Kempler, P. A.; Gonzalez, M. A.; Papadantonakis, K. M.; Lewis, N. S., Hydrogen evolution with minimal parasitic light absorption by dense Co-P catalyst films on structured p-Si photocathodes. ACS Energy Lett. 2018, 3 (3), 612-617.

15. Roske, C. R.; Popczun, E. J.; Seger, B.; Read, C. G.; Pedersen, T.; Hansen, O.; Vesborg, P. C. K.; Brunschwig, B. S.; Schaak, R. E.; Chorkendorff, I.; et al. Comparison of the oerformance of CoP-Coated and Pt-Coated radial junction $\mathrm{n}^{+} \mathrm{p}$-Si microwire-array photocathodes for the sunlight-driven reduction of water to $\mathrm{H}_{2}(\mathrm{~g})$. J. Phys. Chem. Lett. 2015, 6 (9), 1679-1683. 16. Vijselaar, W.; Tiggelaar, R. M.; Gardeniers, H.; Huskens, J., Efficient and stable silicon microwire photocathodes with a nickel silicide interlayer for operation in strongly alkaline solutions. ACS Energy Lett. 2018, 3 (5), 1086-1092.

17. Vijselaar, W.; Westerik, P.; Veerbeek, J.; Tiggelaar, R. M.; Berenschot, E.; Tas, N. R.; Gardeniers, H.; Huskens, J., Spatial decoupling of light absorption and catalytic activity of NiMo-loaded high-aspect-ratio silicon microwire photocathodes. Nat. Energy 2018, 3 (3), 185. 18. Hu, Y.; Chen, F.; Ding, P.; Yang, H.; Chen, J.; Zha, C.; Li, Y., Designing effective Si/Ag interface via controlled chemical etching for photoelectrochemical $\mathrm{CO}_{2}$ reduction. J. Mat. Chem. $A$ 2018, 6 (44), 21906-21912.

19. Kong, Q.; Kim, D.; Liu, C.; Yu, Y.; Su, Y.; Li, Y.; Yang, P., Directed assembly of nanoparticle catalysts on nanowire photoelectrodes for photoelectrochemical $\mathrm{CO}_{2}$ reduction. Nano Lett. 2016, 16 (9), 5675-5680.

20. Hinogami, R.; Mori, T.; Yae, S.; Nakato, Y., Efficient photoelectrochemical reduction of carbon dioxide on a p-type silicon ( $\mathrm{p}-\mathrm{Si}$ ) electrode modified with very small copper particles. Chemistry letters 1994, 23 (9), 1725-1728. 
21. Cottineau, T.; Morin, M.; Bélanger, D., Modification of p-type silicon for the photoelectrochemical reduction of $\mathrm{CO}_{2}$. ECS Trans. 2009, 19 (35), 1-7.

22. Gurudayal; Beeman, J. W.; Bullock, J.; Wang, H.; Eichhorn, J.; Towle, C.; Javey, A.; Toma, F. M.; Mathews, N.; Ager, J. W., Si photocathode with Ag-supported dendritic Cu catalyst for $\mathrm{CO}_{2}$ reduction. Energy Environ. Sci. 2019, 12 (3), 1068-1077.

23. McIntosh, K. R.; Baker-Finch, S. C. In OPAL 2: Rapid optical simulation of silicon solar cells, 2012 38th IEEE Photovoltaic Specialists Conference, IEEE: 2012; pp 000265-000271.

24. Yalamanchili, S.; Kempler, P. A.; Papadantonakis, Kimberly M.; Atwater, H. A.; Lewis, N. S., Integration of electrocatalysts with silicon microcone arrays for minimization of optical and overpotential losses during sunlight-driven hydrogen evolution. Sus. Energy Fuels 2019, 3 (9), 2227-2236.

25. Bard, A. J.; Faulkner, L. R.; Leddy, J.; Zoski, C. G., Electrochemical Methods: Fundamentals and Applications. Wiley New York: 1980; Vol. 2.

26. Kim, J.; Summers, D.; Frese Jr, K., Reduction of $\mathrm{CO}_{2}$ and $\mathrm{CO}$ to methane on $\mathrm{Cu}$ foil electrodes. J. Electroanal. Chem. Interfacial Electrochem. 1988, 245 (1-2), 223-244.

27. Valkonen, E.; Karlsson, B.; Ribbing, C., Solar optical properties of thin films of Cu, Ag, $\mathrm{Au}, \mathrm{Cr}, \mathrm{Fe}, \mathrm{Co}, \mathrm{Ni}$ and Al. Solar Energy 1984, 32 (2), 211-222.

28. Hellstern, T. R.; Nielander, A. C.; Chakthranont, P.; King, L. A.; Willis, J. J.; Xu, S.; MacIsaac, C.; Hahn, C.; Bent, S. F.; Prinz, F. B., Nanostructuring Strategies To Increase the Photoelectrochemical Water Splitting Activity of Silicon Photocathodes. ACS Appl. Nano Mat. 2019, 2 (1), 6-11. 
29. Kuhl, K. P.; Hatsukade, T.; Cave, E. R.; Abram, D. N.; Kibsgaard, J.; Jaramillo, T. F., Electrocatalytic conversion of carbon dioxide to methane and methanol on transition metal surfaces. J. Amer. Chem. Soc. 2014, 136 (40), 14107-14113.

30. Dinh, C.-T.; García de Arquer, F. P.; Sinton, D.; Sargent, E. H., High rate, selective, and stable electroreduction of $\mathrm{CO}_{2}$ to $\mathrm{CO}$ in basic and neutral media. ACS Energy Lett. 2018, 3 (11), 2835-2840.

31. Dinh, C.-T.; Burdyny, T.; Kibria, M. G.; Seifitokaldani, A.; Gabardo, C. M.; de Arquer, F. P. G.; Kiani, A.; Edwards, J. P.; De Luna, P.; Bushuyev, O. S., $\mathrm{CO}_{2}$ electroreduction to ethylene via hydroxide-mediated copper catalysis at an abrupt interface. Science 2018, 360 (6390), 783-787.

32. Schreier, M.; Héroguel, F.; Steier, L.; Ahmad, S.; Luterbacher, J. S.; Mayer, M. T.; Luo, J.; Grätzel, M., Solar conversion of $\mathrm{CO}_{2}$ to $\mathrm{CO}$ using earth-abundant electrocatalysts prepared by atomic layer modification of CuO. Nat. Energy 2017, 2 (7), 17087.

33. Gurudayal, G.; Bullock, J.; Srankó, D. F.; Towle, C. M.; Lum, Y.; Hettick, M.; Scott, M. C.; Javey, A.; Ager, J., Efficient solar-driven electrochemical $\mathrm{CO}_{2}$ reduction to hydrocarbons and oxygenates. Energy Environ. Sci. 2017, 10 (10), 2222-2230.

34. Vijselaar, W. J.; Perez-Rodriguez, P.; Westerik, P. J.; Tiggelaar, R. M.; Smets, A. H.; Gardeniers, H.; Huskens, J., A stand-alone Si-based porous photoelectrochemical cell. Adv. Energy Mat. 2019, 9 (19), 1803548.

35. Boettcher, S. W.; Warren, E. L.; Putnam, M. C.; Santori, E. A.; Turner-Evans, D.; Kelzenberg, M. D.; Walter, M. G.; McKone, J. R.; Brunschwig, B. S.; Atwater, H. A.; Lewis, N.S., Photoelectrochemical hydrogen evolution using Si microwire arrays. J. Amer. Chem. Soc. 2011, $133(5), 1216-1219$. 
36. Hall, A. S.; Yoon, Y.; Wuttig, A.; Surendranath, Y., Mesostructure-induced selectivity in $\mathrm{CO}_{2}$ reduction catalysis. J. Amer. Chem. Soc. 2015, 137 (47), 14834-14837.

37. Welch, A. J.; DuChene, J. S.; Tagliabue, G.; Davoyan, A.; Cheng, W.-H.; Atwater, H. A., Nanoporous gold as a highly selective and active carbon dioxide reduction catalyst. ACS Appl. Energy Mat. 2018, 2 (1), 164-170.

38. Chen, Y.; Lewis, N. S.; Xiang, C., Operational constraints and strategies for systems to effect the sustainable, solar-driven reduction of atmospheric $\mathrm{CO}_{2}$. Energy Environ. Sci. 2015, 8 (12), 3663-3674. 